\title{
How much does traffic contribute to benzene and polycyclic aromatic hydrocarbon air pollution? Results from a high-resolution North American air quality model centred on Toronto, Canada
}

\author{
Cynthia H. Whaley ${ }^{1,2}$, Elisabeth Galarneau ${ }^{1}$, Paul A. Makar ${ }^{1}$, Michael D. Moran ${ }^{1}$, and Junhua Zhang ${ }^{1}$ \\ ${ }^{1}$ Air Quality Research Division, Environment and Climate Change Canada, Toronto, Ontario, Canada \\ ${ }^{2}$ Climate Research Division, Environment and Climate Change Canada, Victoria, British Columbia, Canada
}

Correspondence: Elisabeth Galarneau (elisabeth.galarneau@canada.ca)

Received: 25 September 2019 - Discussion started: 17 October 2019

Revised: 27 January 2020 - Accepted: 9 February 2020 - Published: 11 March 2020

\begin{abstract}
Benzene and polycyclic aromatic hydrocarbons (PAHs) are toxic air pollutants that have long been associated with motor vehicle emissions, though the importance of such emissions has never been quantified over an extended domain using a chemical transport model. Herein we present the first application of such a model (GEM-MACH-PAH) to examine the contribution of motor vehicles to benzene and PAHs in ambient air. We have applied the model over a region that is centred on Toronto, Canada, and includes much of southern Ontario and the northeastern United States. The resolution $(2.5 \mathrm{~km})$ was the highest ever employed by a model for these compounds in North America, and the model domain was the largest at this resolution in the world to date. Using paired model simulations that were run with vehicle emissions turned on and off (while all other emissions were left on), we estimated the absolute and relative contributions of motor vehicles to ambient pollutant concentrations. Our results provide estimates of motor vehicle contributions that are realistic as a result of the inclusion of atmospheric processing, whereas assessing changes in benzene and PAH emissions alone would neglect effects caused by shifts in atmospheric oxidation and particle-gas partitioning. A secondary benefit of our scenario approach is in its utility in representing a fleet of zero-emission vehicles (ZEVs), whose adoption is being encouraged in a variety of jurisdictions. Our simulations predicted domain-average on-road vehicle contributions to benzene and PAH concentrations of $4 \%-21 \%$ and $14 \%-24 \%$ in the spring-summer and fall-winter periods, respectively, depending on the aromatic compound. Contributions to PAH
\end{abstract}

concentrations up to $50 \%$ were predicted for the Greater Toronto Area, and the domain maximum was simulated to be $91 \%$. Such contributions are substantially higher than those reported at the national level in Canadian emissions inventories, and they also differ from inventory estimates at the subnational scale in the US. Our model has been run at a finer spatial scale than reported in those inventories, and furthermore includes physico-chemical processing that alters pollutant concentrations after their release. The removal of onroad vehicle emissions generally led to decreases in benzene and PAH concentrations during both periods that were studied, though atmospheric processing (such as chemical reactions and changes to particle-gas partitioning) contributed to non-linear behaviour at some locations or times of year. Such results demonstrate the added value associated with regional air quality modelling relative to examinations of emissions inventories alone. We also found that removing on-road vehicle emissions reduced spring-summertime surface $\mathrm{O}_{3}$ volume mixing ratios and fall-wintertime $\mathrm{PM}_{10}$ concentrations each by $\sim 10 \%$ in the model domain, providing further air quality benefits. Toxic equivalents contributed by vehicle emissions of PAHs were found to be substantial (20\%-60\% depending on location), and this finding is particularly relevant to the study of public health in the urban areas of our model domain where human population, ambient concentrations, and traffic volumes tend to be high. 


\section{Introduction}

Emissions from motor vehicles have been linked to air quality degradation (e.g., WHO, 2005; Han and Naeher, 2006; Zhang and Batterman, 2013; Farrell et al., 2016; Zimmerman et al., 2016; Gentner et al., 2017; Wang et al., 2017) and greenhouse gas pollution (e.g., Sims et al., 2014; Zimmerman et al., 2016; Boulton, 2016; US EPA, 2002) globally. In North America, vehicle emission controls have gradually reduced emissions of many pollutants and made vehicles more fuel efficient (U.S. Environmental Protection Agency, 2012; Reid and Aherne, 2016), with transportation policies being closely aligned in Canada and the United States (ECCC, 2019b). The Canadian and US governments promote the benefits of zero-emission vehicles (ZEVs) (Transport Canada, 2019; energy.gov, 2020), and several jurisdictions in both countries have adopted strategies to increase ZEV use (e.g., Government of Quebec, 2020; Center for climate and energy solutions, 2019; Government of Canada, 2019). Additionally, the phaseout of high-emission electricity generation has already begun, with Ontario's power generation $95 \%$ emissions free as of 2017 (61\% nuclear, $27 \%$ hydro, $7 \%$ wind and solar; ECCC, 2019a). With this rapidly approaching future in mind, atmospheric chemistry models are useful tools for predicting the expected changes in pollutant concentrations that will result from a continuing reduction in vehicle emissions.

Of particular interest are highly toxic pollutants such as benzene and polycyclic aromatic hydrocarbons (PAHs), which are ubiquitous in the environment and include compounds that are carcinogenic, mutagenic, and teratogenic. In Canada, both have been subject to risk management under the Canadian Environmental Protection Act (CEPA) with actions focused on emergency management, fuel composition, and emitting activities associated with the natural gas, aluminum, iron and steel, and wood preservation industries (ECCC, 2015, 2018b). Ontario, Canada's most populous province and home to the nation's largest city, Toronto, has developed health-based ambient air quality criteria for these pollutants, but these are exceeded at many locations throughout the country (Galarneau et al., 2016) despite the actions taken under CEPA. In the US, benzene and PAHs have been identified as contributors to excess cancer risk under the National Air Toxics Assessment (NATA) program (EPA, 2015).

National benzene emissions in Canada are compiled through the National Pollutant Release Inventory (NPRI) (NPRI, 2016) but only for major industrial, commercial, and institutional sources. Previous model-based estimates (Stroud et al., 2016) suggest that $40 \%-54 \%$ of benzene in the ambient air of major Canadian cities is due to mobile sources (e.g., cars, trains, ships), which are not included in the NPRI. In the US, the most recent National Emissions Inventory (NEI) (US EPA, 2018) includes benzene emissions estimates from a variety of natural and anthropogenic sources. At the national scale, $47 \%$ (90 kt) of benzene emis- sions in the US are estimated to arise from mobile sources, of which $60 \%(54 \mathrm{kt})$ is from on-road vehicles (e.g., cars, trucks, motorcycles). Those on-road vehicle contributions range from $0 \%-84 \%$ of total benzene emissions when reported at the county or tribal level.

Canadian emissions of four PAHs (benzo[b]fluoranthene, benzo[k]fluoranthene, benzo[a]pyrene, and indeno[1,2,3cd]pyrene) from all known anthropogenic sources are estimated through the comprehensive national Air Pollutant Emission Inventory (APEI) (ECCC, 2018a), whose major point-source emissions are reported through the NPRI. Mobile source contributions in the APEI accounted for $8.3 \%(2629 \mathrm{~kg})$ of the total anthropogenic emissions of benzo[a]pyrene $(31516 \mathrm{~kg}$ ) in 2017 , the most recent data year available, consistent with Environment Canada and Health Canada (1994) and Galarneau et al. (2007). In the US, the 2014 NEI (US EPA, 2018) reports that on-road vehicle emissions are $20 \%$ (28931 kg) of total national anthropogenic benzo[a]pyrene (BaP) emissions (145 $102 \mathrm{~kg})$. Relative mobile source contributions are expected to be greater in urban centres (Nielsen, 1996; Harrison et al., 1996; Dunbar et al., 2001; Shen et al., 2011; Pachón et al., 2013; Kuoppamäki et al., 2014; Miao et al., 2015) than they are at the national scale due to the spatial concentration of urban onroad vehicle use and the tendency of large industrial sources to be located outside those cities.

Here, we make use of a recently developed and validated high-resolution online chemical transport model (GEMMACH-PAH; Whaley et al., 2018b) to study the impact of on-road vehicle emissions on ambient concentrations of benzene and a suite of PAHs in a regional domain centred over Toronto, Canada, that includes much of southern Ontario and the northeastern US (Fig. 1). GEM-MACH-PAH was run with identical meteorology for two emissions cases: (1) a base case with all emissions of all species and sectors included and (2) a no mobile case with emissions of all species from on-road vehicles set to zero (benzene, PAHs, and criteria air contaminants (CACs) such as $\mathrm{NO}_{x}, \mathrm{CO}$, VOCs, PM, etc.). The vehicle contributions are determined from the difference between the base and no mobile cases, and this strategy has permitted us to calculate vehicle contributions in a realistic way that incorporates not only the effect of benzene and PAH emissions, but also the effect of atmospheric processing caused by the changes to CACs emitted by motor vehicles. The no mobile scenario has additionally allowed us to quantify the impact of a hypothetical future ZEV fleet, whose adoption is being encouraged in a variety of jurisdictions. We did not simulate biofuel emission scenarios, as those fuels have sometimes been shown to increase PAH emissions rather than reduce them (Karavalakis et al., 2011), and further work is needed before they can be simulated with confidence.

These simulations provide consistent information about the spatial distribution of concentrations and on-road vehicle contributions for benzene and PAHs. While other PAH chemical transport models exist (Aulinger et al., 2007; Friedman 


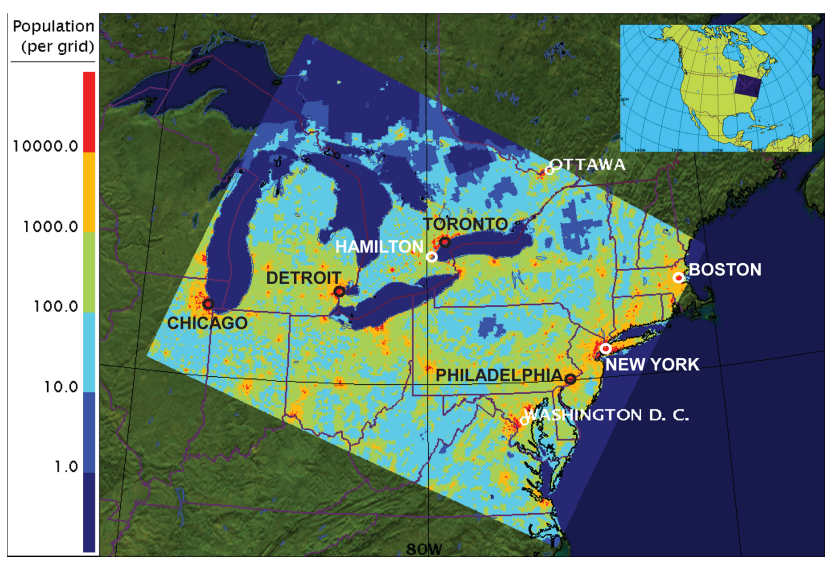

Figure 1. Model domain, coloured on a logarithmic scale by the human population per $2.5 \mathrm{~km} \times 2.5 \mathrm{~km}$ model grid cell.

and Selin, 2012; San José et al., 2013; Gariazzo et al., 2014; Gariazzo et al., 2015; Thackray et al., 2015; Zhang et al., $2016,2017)$, this is the first study to use such a model to evaluate traffic contributions to ambient air and assess the change in resulting airborne toxicity. Our simulations also have the highest resolution employed to date in a North American domain, and the largest high-resolution domain compared to other PAH modelling studies anywhere in the world.

\section{Methods}

\subsection{Model description}

GEM-MACH (Moran et al., 2010) (Global Environment Multiscale Modelling Air quality and CHemistry) is an online chemical transport model driven by meteorological fields produced by the GEM numerical weather prediction model (Côté et al., 1998b, a). The model was recently adapted to include the emission, advection and diffusion, deposition, and chemical degradation of benzene (BENZ) and seven PAHs: phenanthrene (PHEN), anthracene (ANTH), fluoranthene (FLRT), pyrene (PYR), benz[a]anthracene (BaA), chrysene (CHRY), and benzo[a]pyrene (BaP) (Whaley et al., 2018b). While BENZ in ambient air is gaseous, PAHs are semi-volatile species that are found in both the gas and particle phases. Their particle-gas partitioning in GEM-MACHPAH is determined via the Dachs-Eisenreich scheme (Dachs and Eisenreich, 2000; Whaley et al., 2018b). Section I of the Supplement provides further information on $\mathrm{PAH}$ process representations within the model.

GEM-MACH-PAH was run at $2.5 \mathrm{~km}$ horizontal grid spacing on a domain that includes large North American urban areas such as Toronto, New York City, Chicago, Washington DC, Philadelphia, Boston, and Detroit (Fig. 1).

Two time periods in 2009 were chosen (spring-summer, 13 May to 13 August, and fall-winter, 23 October to 5 Jan- uary 2010) to balance the computational demands required for this model (IBM Power7 supercomputer) against the ability to examine seasonal differences and include evaluation data from a temporally coincident high-density campaign conducted in 2009 west of Toronto (Anastasopoulos et al., 2012). Additional details about the model setup and run strategy are provided in the Supplement (Sect. I).

\subsection{Emissions}

Hourly, gridded, and speciated input emission fields were prepared using the Sparse Matrix Operator Kernel Emissions system (SMOKE; https://www.cmascenter.org/smoke, last access: 6 March 2020, Houyoux et al., 2002), making use of criteria air pollutant emissions from Canada's 2010 APEI (Sassi et al., 2015) reported by province and US EPA 2011 NEI (Eyth et al., 2013) emissions reported at the county or tribal level. BENZ and PAHs were speciated relative to aggregate $\mathrm{VOC}$ emissions using VOC speciation profiles from the Canadian Emissions Processing System (Moran et al., 1997) for BENZ and special speciation profiles developed by Galarneau et al. (2007, 2014), and Whaley et al. (2018b) for PAHs. PAH emissions from on-road mobile sources were calculated from VOC emissions generated using MOBILE 6.2C (EPA, 2002) and MOVES 2010b (https://www.epa.gov/moves/ moves2014-and-moves2010b-versions-limited-current-use, last access: 6 March 2020) for Canada and the US, respectively. PAH species emissions were estimated using $\mathrm{PAH}$-to-VOC and PAH-to-organic carbon emission ratios from MOVES2014 converted to a total organic gas (TOG) basis. Note that reported emission factors (EFs) for PAHs in the literature are highly variable. Different EFs were tested in the model but those from MOVES2014 achieved the best results compared to observations (Whaley et al., 2018b).

SMOKE uses spatial surrogate fields to distribute vehicle emissions reported for each jurisdiction (e.g., provinces in Canada, counties in the US) among model grid cells. Unlike the MOBILE 6.2C-based inventory for Canada, the MOVES2010b-based inventory for the US explicitly includes an "off-network" road type that accounts for emissions when vehicles are stationary (e.g., idle, parked, starting, or refuelling), and this road type contributes $\sim 60 \%$ of on-road emissions (NEI2011). The effect of this spatialallocation difference between the MOBILE and MOVES inventories on the modelled on-road vehicle contributions of BENZ and PAH is presented later in this work.

To construct the emissions fields for the no mobile case, emissions from all area sources, off-road mobile sources (e.g., trains, boats, snowmobiles, aircraft, etc.), and minor point sources present in the base case were retained, but all on-road vehicle emissions (of all species) were removed. 


\subsection{Model evaluation summary}

Detailed model descriptions and evaluations of GEM-MACH have been published for pollutants other than benzene and PAHs (Moran et al., 2010; Moran et al., 2013; Makar et al., 2015b, a; Gong et al., 2015; Whaley et al., 2018a). The GEM-MACH-PAH base simulation used for the current study was previously evaluated in the most rigorous comparison to measurements yet published for such a model at fine spatial resolution (Whaley et al., 2018b). That evaluation compared GEM-MACH-PAH output to benzene and PAH measurements from 121 and 35 network sites, respectively, from Canada's National Air Pollution Surveillance program (NAPS), the US National Air Toxics Trends Stations (NATTS), and the Canada-US Integrated Atmospheric Deposition Network (IADN), which all record $24 \mathrm{~h}$ integrated air concentrations every one in six consecutive days, at locations associated with a variety of population densities and land uses (e.g., urban, suburban, industrial, and rural locations). Additional 2-week integrated PAH measurements from 46 sites in a high-spatial-density campaign conducted in Hamilton, Ontario, Canada, in spring-summer and fallwinter 2009 (Anastasopoulos et al., 2012) were also used to assess concentration variability within a city as well as within model grid squares (the Supplement, Sect. I).

Ratios of modelled-to-measured concentrations were generally within an order of magnitude of unity, with median values in spring-summer being lower for BENZ and PAHs with molecular weights of $178-202 \mathrm{~g} \mathrm{~mol}^{-1}(0.31-0.86)$ compared to PAHs with molecular weights of $228-252 \mathrm{~g} \mathrm{~mol}^{-1}$ (1.8-8.4). Fall-winter values were modestly higher (1.5-9.9) though still within an order of magnitude of unity. Further details can be found in Whaley et al. (2018b). Modelled concentrations were found to be statistically unbiased relative to measurements (paired $t$ test with $t<1, p>0.01$ ) for all compounds and seasons except for BaP in fall-winter (Whaley et al., 2018b), which was biased high. Model output for the latter compound and season combination was therefore excluded from this study. Fall-winter BENZ was also excluded from this study because of an important missing sector discovered in the fall-wintertime BENZ emissions. Please refer to the Supplement, Sect. I, for more information.

GEM-MACH-PAH's particle-gas partitioning parametrization was evaluated at six IADN stations, and the results showed a substantial improvement over the previous AURAMS-PAH partitioning (Galarneau et al., 2014) due to an empirically based update in partitioning parameters (Whaley et al., 2018b).

The sensitivity of model results for partitioning and other parameters (e.g., oxidant concentrations) is examined in Sect. 3.7 and in the Supplement. Good overall performance of GEM-MACH-PAH has been demonstrated by comparison to measurements as discussed above, with more details in Whaley et al. (2018b), and our sensitivity analyses further support the model's validity for calculating ambient concen- trations and for assessing source contributions at its evaluated resolution ( $2.5 \mathrm{~km}$ grid size and seasonal timescale).

\section{Results}

Spatial distributions of modelled concentrations and vehicle contributions were similar for BENZ and the seven PAHs. As a result, we focus on a few representative species in this section, and show results for the remaining species in the Supplement.

\subsection{Benzene and PAH concentrations from the base case}

Modelled base case (all emissions activated) average airborne concentrations of BENZ, PHEN, PYR, and BaP are shown in Fig. 2 for the spring-summer and Fig. S2a in the Supplement for the fall-winter. The three PAH compounds exhibit a range of volatilities. PHEN and $\mathrm{BaP}$ are found predominantly in the gas and particle phases, respectively, whereas PYR, with a mid-range volatility, is typically found in both. The spatial distribution of concentrations is similar to the distribution of human population shown in Fig. 1 as expected from the prevalence of anthropogenic sources in the study area.

Modelled concentrations for BENZ and PAHs are higher in fall-winter than in spring-summer (Whaley et al., 2018b) due to lower fall-winter temperatures and solar radiation. These factors lead to reduced photochemical degradation and increased vertical stability, which in turn induce less vertical mixing and dilution and lower boundary layer heights. Thus, ambient concentrations are higher per unit emission in fallwinter than in spring-summer. Additionally, total emissions for PAHs are higher in fall-winter than in spring-summer (Fig. S3a) due to increased on-road vehicle emissions (e.g., cold starts) and combined area and off-road mobile sources (e.g., heating, snowmobiling). Note that different rates of PAH oxidation in the different seasons are expected to lead to different rates of production of secondary products such as oxy- and nitro-PAHs. These secondary products are not yet included in GEM-MACH-PAH due to uncertainties in their sources and properties, but they are under consideration for future addition to the modelling package given that some of these compounds are more toxic than their parent PAHs.

\subsection{Absolute on-road vehicle contributions}

Figures 3 and S2b (in the Supplement) show the contribution of on-road vehicles to ambient concentrations in the springsummer and fall-winter, respectively, as represented by the absolute differences in concentrations between the base and no mobile cases. Concentrations in the no mobile case are significantly lower than those for the base case as expected from the lack of on-road vehicle emissions. 


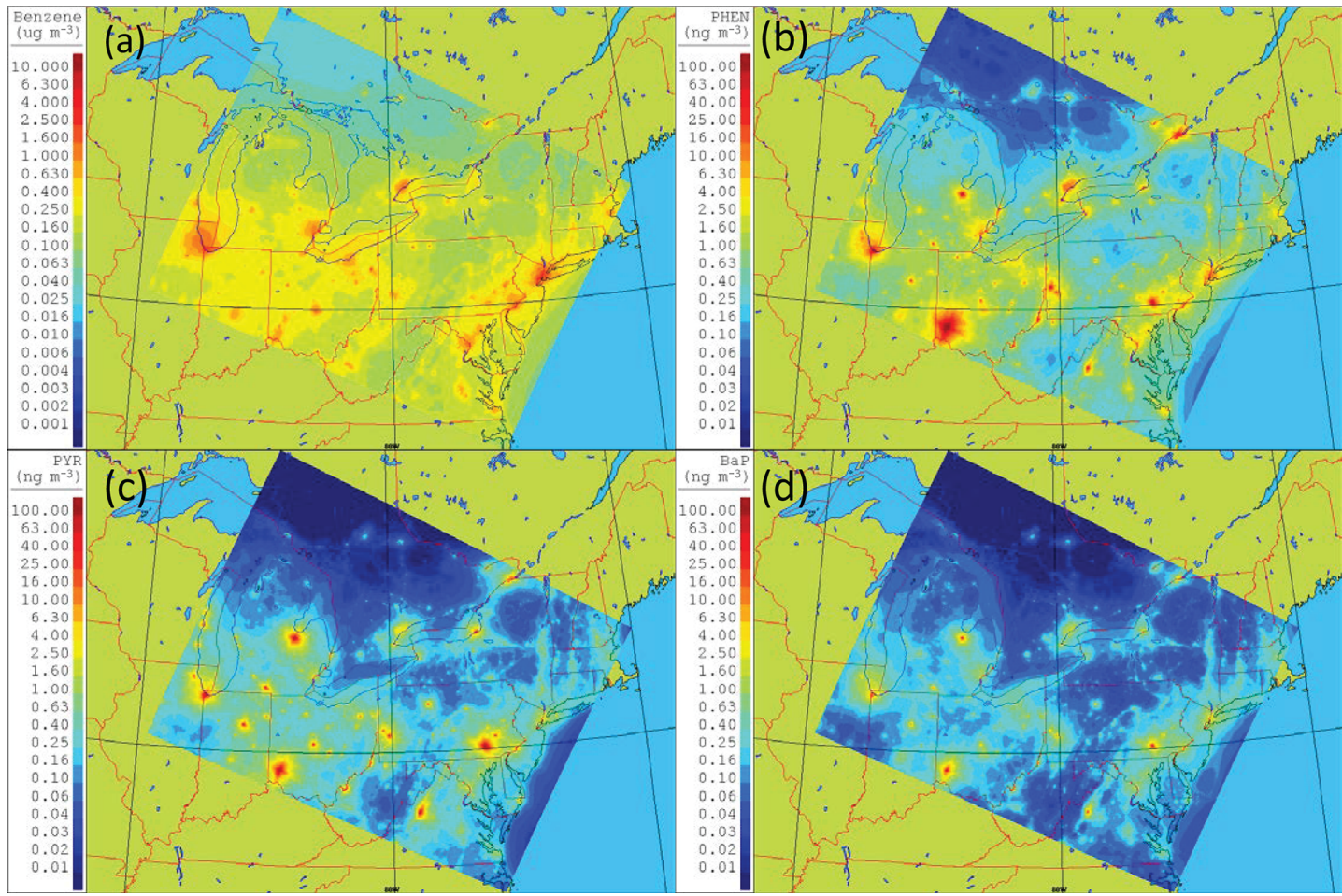

Figure 2. Modelled average airborne concentrations for (a) BENZ, (b) PHEN, (c) PYR, and (d) BaP in the spring-summer.

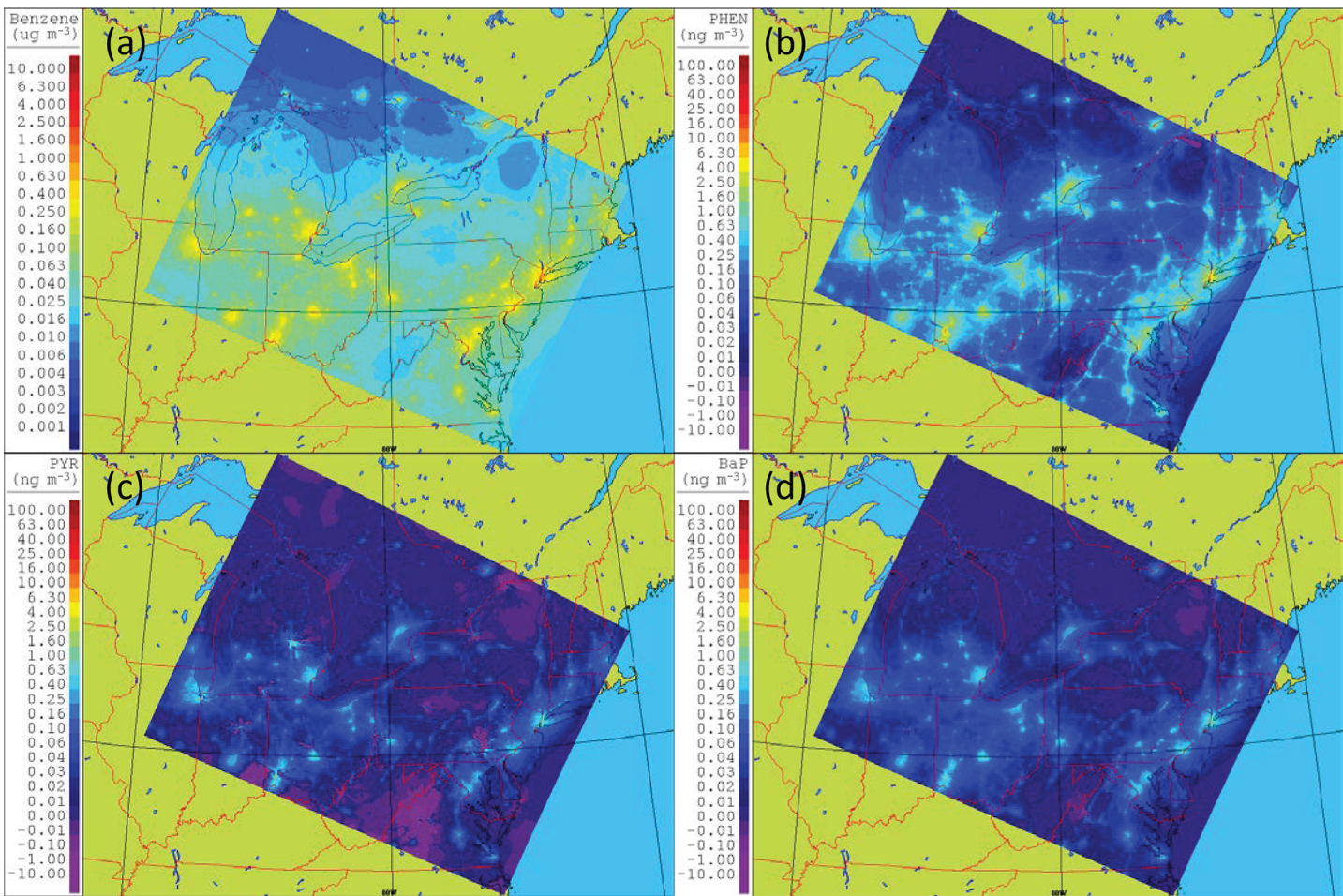

Figure 3. Seasonal-average absolute on-road vehicle contributions for (a) BENZ, (b) PHEN, (c) PYR, and (d) BaP in the spring-summer. 
Major cities are prominent in Fig. 3 for all species as expected given the high urban traffic volumes. In the Greater Toronto Area (GTA), BENZ concentrations due to on-road vehicles in spring-summer are on the order of 0.1$0.3 \mu \mathrm{g} \mathrm{m}^{-3}$ (Fig. S4) and these values are similar to those of other urban centres in Ontario such as Hamilton. Springsummer contributions up to $0.5-0.9 \mu \mathrm{g} \mathrm{m}^{-3}$ of BENZ are seen in the large urban centres of the US such as New York City, Chicago, and Washington DC (Fig. S4) as well as in several smaller US cities (Fig. 3).

Spatial distributions of absolute on-road mobile source contributions for the PAHs are similar to those for BENZ. Spring-summer contributions in the GTA for PHEN, PYR, and $\mathrm{BaP}$ are approximately $2.0,0.35$, and $0.3 \mathrm{ng} \mathrm{m}^{-3}$, respectively, and slightly higher in fall-winter for the species reported in Fig. S2b. Absolute contributions from on-road vehicles are higher in the major US urban areas than they are in the Canadian cities (examples for BENZ and PYR shown in Fig. S4). These cross-border differences arise in part because of differences in the spatial surrogates mentioned above and the different emissions inventories (see Sect. 2.2 and the Supplement, Sect. IV). Furthermore, the cities in the US portion of the study region have populations that are larger on average than the cities in the Canadian portion, and concentrations of PAHs have been shown to increase in direct proportion to human population (Hafner et al., 2005).

However, there are some geographically limited exceptions where the removal of on-road vehicle emissions causes PAH concentrations to increase slightly (areas with negative values in Fig. 3): in the spring-summer there are small concentration increases in the northeastern portion of New York State and along the border between Virginia and West Virginia. These apparent anomalies are located where base PAH concentrations are already relatively low, and are consistent with the impacts on oxidant chemistry discussed below and in the Supplement (Sect. V). In fall-winter, PAH increases in the no mobile case are confined to two small regions near the domain borders (Fig. S2b), where factors other than the emission change may be responsible (e.g., boundary effects, numerical issues, etc.).

Nevertheless, measurements show that Ontario's annual ambient air quality criteria for BENZ $\left(0.45 \mu \mathrm{g} \mathrm{m}^{-3}\right)$ and BaP $\left(0.01 \mathrm{n} \mathrm{m}^{-3}\right)$, the latter of which is used by the province as a surrogate for PAHs, are exceeded in Toronto, Hamilton, and Windsor (Galarneau et al., 2016). The absolute contributions of on-road vehicles in those areas (Fig. 3) suggest that reducing their emissions could assist in reducing those exceedances. Policies and programs seek to achieve air quality benefits with minimal socioeconomic cost, thus knowledge of the relative (e.g., percent) contributions of different sources is an important criterion for prioritizing possible management actions. The reduction in on-road vehicle emissions will only be effective in achieving meaningful reductions in ambient concentrations if their local contributions are significant relative to the total.

\subsection{Relative on-road vehicle contributions}

The relative contributions (expressed as the percentage of the base case concentrations) of on-road vehicles to BENZ, PHEN, PYR, and BaP concentrations are shown as maps and frequency distributions of domain-wide ranges in Figs. 4 and 5, respectively, with maps for the remaining PAH species shown in Figs. S2c and S8. Domain-wide average and maximum values are also listed in Table 1 and shown in Fig. 5. Relative on-road vehicle contributions to PAH concentrations in individual model grid squares had maxima as high as $64 \%-91 \%$ in spring-summer. Maxima were slightly lower in fall-winter (49\%-72\%) for the subset of PAHs reported for that period (Figs. 5 and S2c, and Table 1). Domain means, however, were higher in the fall-winter than in the springsummer (Fig. 5, and Table 1). The highest relative on-road vehicle contributions were observed in or near small cities such as North Bay, Ontario; Columbus and Toledo, Ohio; and Grand Rapids, Michigan, where major highways are found in areas of otherwise low ambient concentrations.

In the spring-summertime, domain-mean on-road vehicle contributions to ambient BENZ in the GTA were on the order of $14 \%-37 \%$, consistent with, though slightly lower than, previously reported values (Stroud et al., 2016) due to the latter study including off-road mobile sources in their "mobile" category. PAH contributions in the GTA ranged from $5 \%$ to $50 \%$, depending on species, season, and proximity to major highways. Even greater contributions were seen in other Canadian cities; thus, our results suggest that fewer and/or less extreme exceedances of provincial BENZ and PAH guidelines could be achieved by reductions in on-road vehicle emissions in cities within the model domain.

This finding is significant in the Canadian policy-making context and demonstrates the value of examining pollutant emissions and concentrations on fine geographic scales. The APEI and other Canadian efforts (Environment Canada and Health Canada, 1994; Galarneau et al., 2007) have estimated that PAH contributions from on-road mobile sources amount to $7 \%-8 \%$ of total anthropogenic PAH emissions at the national scale. (Provincial-scale estimates for BENZ and PAHs are not included in the APEI.) Such minor relative contributions at the national scale could lead to the neglect of the onroad mobile source category in emissions reduction strategies, yet we have shown that this category is important at the local scale in terms of impacts of potential BENZ or PAH management actions.

In the US, NEI emissions are reported at the county or tribal level. On-road vehicle contributions in those reported emissions are closer to this study's high-resolution results in ambient air than are the contributions in emissions reported at the national scale. Nonetheless, on-road vehicle contributions of BENZ and PAHs differ between emissions and ambient air due to physico-chemical processing that occurs in the atmosphere. Such processing varies with time of year and levels of vehicle co-pollutants as described below. 


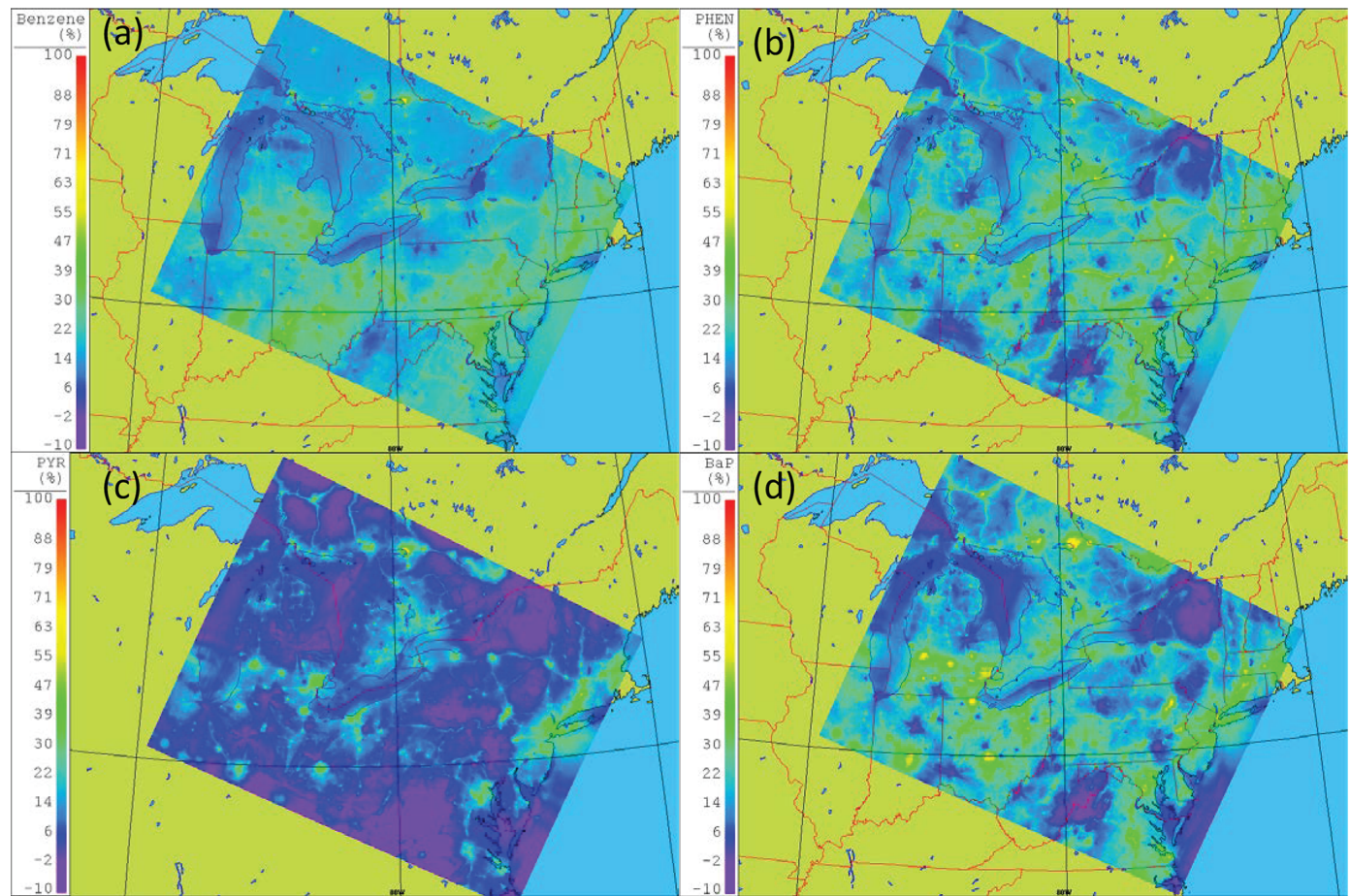

Figure 4. Seasonal-average relative on-road vehicle contributions to ambient concentrations of (a) BENZ, (b) PHEN, (c) PYR, and (d) BaP in the spring-summer.

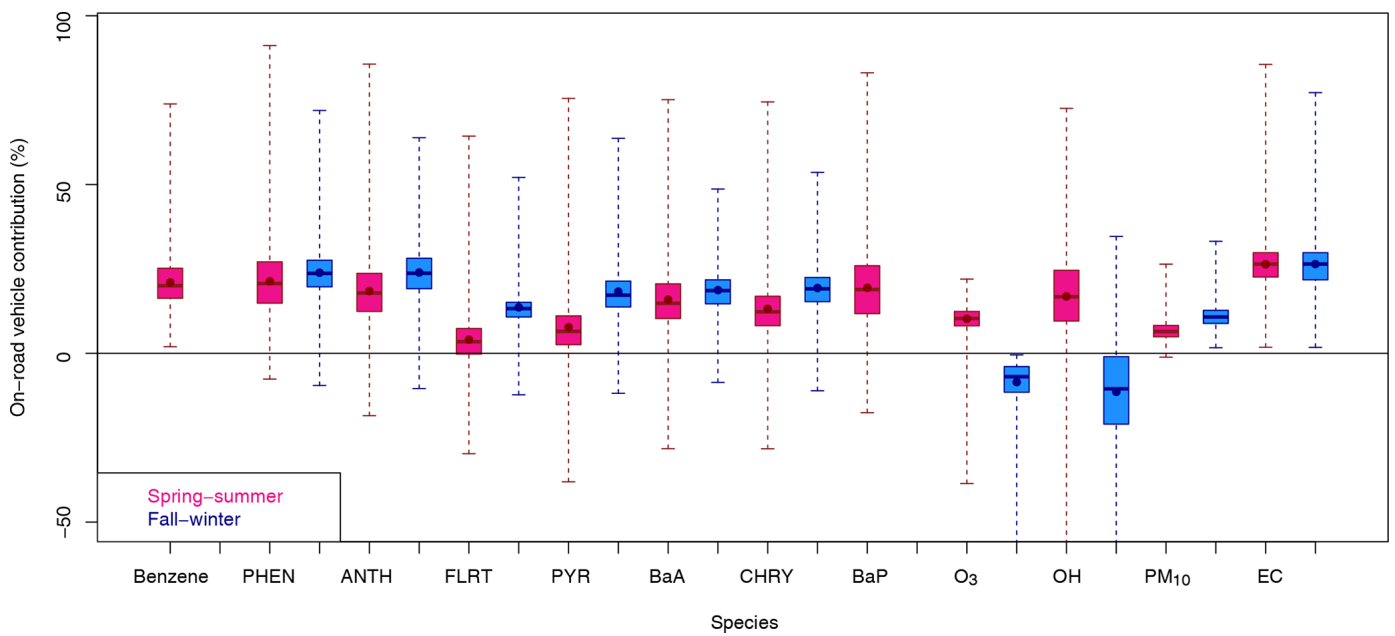

Figure 5. Seasonal-averaged relative on-road vehicle contributions to daily-average surface concentrations (in percent of total) in the model domain for all pollutants studied. Whiskers extend to the maximum range of the data in the domain, the centre line is the domain median, and the dots are the domain average.

\subsection{Seasonal impact on on-road vehicle contributions to benzene and PAHs}

Though PAH emissions from on-road vehicles are higher in fall-winter than in spring-summer (Fig. S3a), the relative contribution of on-road vehicles to total emissions is stable among seasons (viz., domain-average differences between fall-winter and spring-summer emission contribu- tions from on-road vehicles are $-0.6 \%$ and range from $-1.8 \%$ to $+2.7 \%$ for species reported for both time periods; see Fig. S3b).

In contrast, relative on-road vehicle contributions to ambient concentrations differ more between seasons than do their emissions, with differences of $+3 \%$ to $+10 \%$, respectively, between fall-winter and spring-summer (Fig. 5). This suggests that a given relative reduction in on-road vehicle emis- 
Table 1. Domain-wide average and maxima on-road vehicle contribution to ambient concentrations. "NR" represents not reported.

\begin{tabular}{lrrrrrrrr}
\hline & Benzene & PHEN & ANTH & FLRT & PYR & BaA & CHRY & BaP \\
\hline spring-summer avg & $21 \%$ & $21 \%$ & $19 \%$ & $4 \%$ & $8 \%$ & $16 \%$ & $13 \%$ & $19 \%$ \\
spring-summer max & $74 \%$ & $91 \%$ & $86 \%$ & $64 \%$ & $76 \%$ & $75 \%$ & $74 \%$ & $83 \%$ \\
fall-winter avg & NR & $24 \%$ & $24 \%$ & $14 \%$ & $18 \%$ & $19 \%$ & $19 \%$ & NR \\
fall-winter max & NR & $72 \%$ & $64 \%$ & $52 \%$ & $64 \%$ & $49 \%$ & $54 \%$ & NR \\
\hline
\end{tabular}

sions may lead to greater concentration reductions in fallwinter than in spring-summer, and this highlights the importance of conducting analyses that represent conditions at different times of year. The following analysis expands on factors that are potentially responsible for this temporal variability.

\subsection{Oxidant impact on on-road vehicle contributions to benzene and PAHs}

GEM-MACH-PAH includes reactions of BENZ and PAHs with two oxidants: hydroxyl radical $(\mathrm{OH}$, which reacts with BENZ and gaseous PAHs) and ozone $\left(\mathrm{O}_{3}\right.$, which reacts only with particulate $\mathrm{BaP}$ ) (Galarneau et al., 2014; Whaley et al., 2018b). As noted earlier, the no mobile case zeroed on-road vehicle emissions for all emitted chemical species, including precursors to tropospheric $\mathrm{OH}$ and $\mathrm{O}_{3}$, such as $\mathrm{NO}_{x}, \mathrm{CO}$, and VOCs. Thus, the removal of vehicle emissions impacts not only the concentrations of the pollutants of BENZ and PAH directly, but also modifies the concentrations of the oxidants responsible for their chemical degradation.

In the spring-summer, the removal of on-road vehicle emissions of criteria air pollutants leads to $\mathrm{OH}$ reductions in most parts of the study region (Fig. 5 and red areas in Fig. S9a). Oxidative removal rates of BENZ and gaseous PAH are thus reduced in those parts of the domain as a result. This contributes to the finding that reductions in BENZ and PAH emissions of $10 \%-27 \%$ associated with the removal of the on-road mobile emissions (Fig. S3b) result in a domain-average concentration reduction to a lesser degree (4\%-21\%) (Table 1). The removal of all mobile on-road emissions decreases oxidant concentrations; hence, BENZ and PAH from other sources are oxidized to a lesser degree, offsetting the reductions in BENZ and PAH associated with the mobile emissions removal itself. Conversely, $\mathrm{OH}$ increases by $10 \%-50 \%$ in some urban cores (e.g., Toronto, Detroit, New York City; blue areas in Fig. S9a) in the springsummer when on-road vehicle emissions are removed, in response to higher $\mathrm{O}_{3}$ levels via reduced $\mathrm{NO}_{x}$ titration, with a similar result over large portions of the study area in fallwinter (blue in Fig. S9b). At these times and locations, a positive feedback is produced, whereby the degradation of BENZ and gaseous PAHs from other sources is accelerated in areas where their emissions from vehicles have been removed.

Similarly, on-road vehicle emissions in spring-summer contribute to a domain-wide median of $\sim 10 \%(\sim 3.5 \mathrm{ppbv})$ to surface $\mathrm{O}_{3}$ volume mixing ratios (Fig. 5). Thus, when vehicle emissions are removed, airborne BaP is reduced less than expected from the emissions reduction because of reduced oxidation of $\mathrm{BaP}$ from $\mathrm{O}_{3}$. However, in and around major cities, the changes in $\mathrm{O}_{3}$ due to on-road vehicles are smaller than $10 \%$, and they are often negative (see blue in Fig. S9c), viz., $\mathrm{O}_{3}$ increases in response to the removal of $\mathrm{NO}_{x}$ from on-road vehicles in this hydrocarbon-limited regime (Sillman, 1995; Kleinman et al., 2000; Sillman and West, 2009; Jing et al., 2014; Zhang et al., 2014), thus increasing oxidation of $\mathrm{BaP}$ from non-mobile sources. The no mobile case degradation of $\mathrm{BaP}$ is thus enhanced in urban areas. This leads to net urban $\mathrm{BaP}$ reductions that are greater than might be expected from the removal of urban $\mathrm{BaP}$ onroad vehicle emissions alone.

\subsection{Effect of elemental carbon on on-road vehicle contributions to PAHs}

PAHs are semi-volatile and their mass is therefore partitioned between the gas and particle phases in ambient air. Particulate fraction (PF) (Junge, 1977), the ratio of the particulate concentration to the total (gaseous + particulate) concentration, is a common descriptor of particle-gas partitioning. Smaller, lighter PAHs have small PFs of about 0 (e.g., for PHEN), whereas larger, heavier PAHs have PFs around 1 (e.g., for BaP), and semi-volatile PAHs like FLRT and BaA fall somewhere in the middle (Fig. 6a, c). The extent of PAH partitioning varies with temperature and with the availability and composition of particulate matter (PM), where the latter is affected by the zeroing of on-road vehicle emissions as discussed below.

On-road mobile source contributions to domain-averaged PM were $7 \%$ in spring-summer and $10 \%$ in fall-winter (Figs. 5 and S9e and f), lower than those for total (gaseous + particulate) PAHs. This suggests that PAH PFs might rise; that is, a greater relative amount of the PAH might partition to the particulate phase if on-road mobile source emissions were reduced, because relatively more PM would be available per unit mass of remaining PAH. However, decreases in PAH PFs were observed in the no mobile case (Fig. 6b, d-f). This was due to the nature of partitioning, which is specific to PM speciation. Elemental carbon (EC) is the prime sorbent for PAHs in the particle-gas partitioning parameterization in the model (Dachs and Eisenreich, 2000). The on-road vehicle contributions of EC averaged $27 \%$ of total EC mass in both 

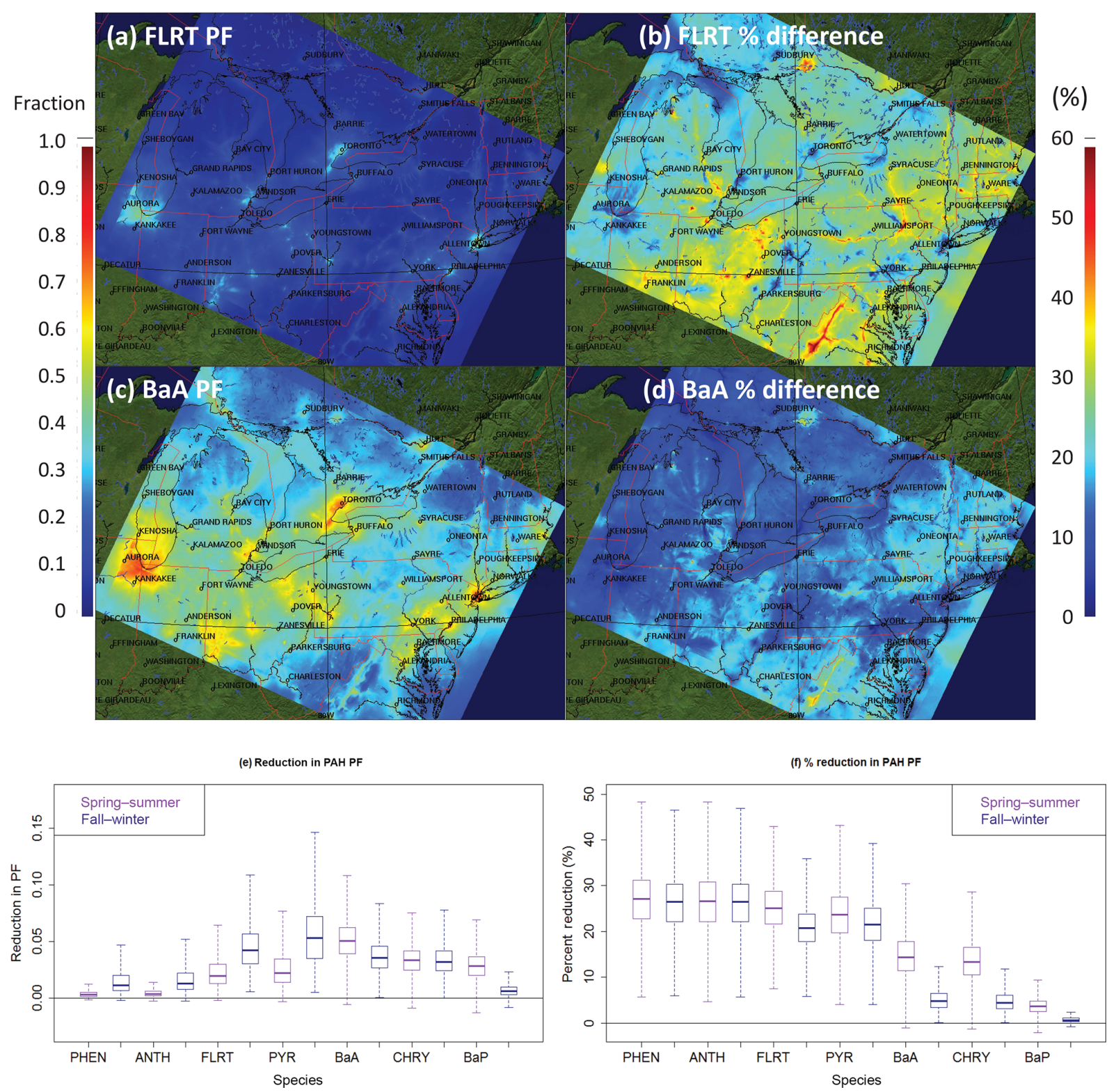

Figure 6. (a, c) Sample maps of particulate fraction (PF) and (b, d) its percent change due to the removal of on-road vehicle emissions. Spring-summer FLRT and BaA are shown as examples. The spring-summer and fall-winter averages of absolute (e) and percent (f) reduction in PF for all PAH species are shown.

seasons (Figs. 5 and S9g and h). Relative to the base case, $\mathrm{EC}$ in the no mobile case was thus reduced to a greater extent than PAH due to the high EC fraction of PM emissions from motor vehicles. This in turn, resulted in the particle-gas partitioning equilibrium being shifted toward the gas phase since less EC mass was available to sorb the remaining PAH. Shifts in particle-gas equilibrium in turn affect removal processes such as deposition and degradation, whose mechanisms differ for gaseous and particulate compounds (Bidleman and Foreman, 1987). Further analysis of the differences in PAH lifetimes that arise from a shift in particle-gas partitioning is beyond the scope of this paper, but it should be kept in mind for future analyses, particularly those that incorporate considerations of transboundary or long-range transport.

\subsection{Sensitivity considerations}

The results described thus far have shown that on-road vehicle emissions contribute substantially to benzene and PAHs in ambient air at a variety of locations in our study area. Differences between seasonal vehicle contributions have been examined with respect to the atmospheric processing that transforms toxic pollutants after they have been emitted to the air. Potential sensitivities of our model results to the un- 
Table 2. Domain-wide average on-road vehicle contributions to ambient concentrations, when on-road vehicle emissions of BENZ and PAHs are halved or doubled. "NR" represents not reported.

\begin{tabular}{|c|c|c|c|c|c|c|c|c|}
\hline & BENZ & PHEN & ANTH & FLRT & PYR & $\mathrm{BaA}$ & CHRY & $\mathrm{BaP}$ \\
\hline spring-summer test with 0.5 times emissions & $11 \%$ & $8 \%$ & $9 \%$ & $0.5 \%$ & $2 \%$ & $7 \%$ & $6 \%$ & $6 \%$ \\
\hline spring-summer test with 2 times emissions & $42 \%$ & $30 \%$ & $33 \%$ & $4 \%$ & $10 \%$ & $27 \%$ & $21 \%$ & $25 \%$ \\
\hline fall-winter test with 0.5 times emissions & NR & $12 \%$ & $4 \%$ & $8 \%$ & $10 \%$ & $11 \%$ & $11 \%$ & NR \\
\hline fall-winter test with 2 times emissions & NR & $41 \%$ & $41 \%$ & $27 \%$ & $34 \%$ & $30 \%$ & $30 \%$ & NR \\
\hline
\end{tabular}

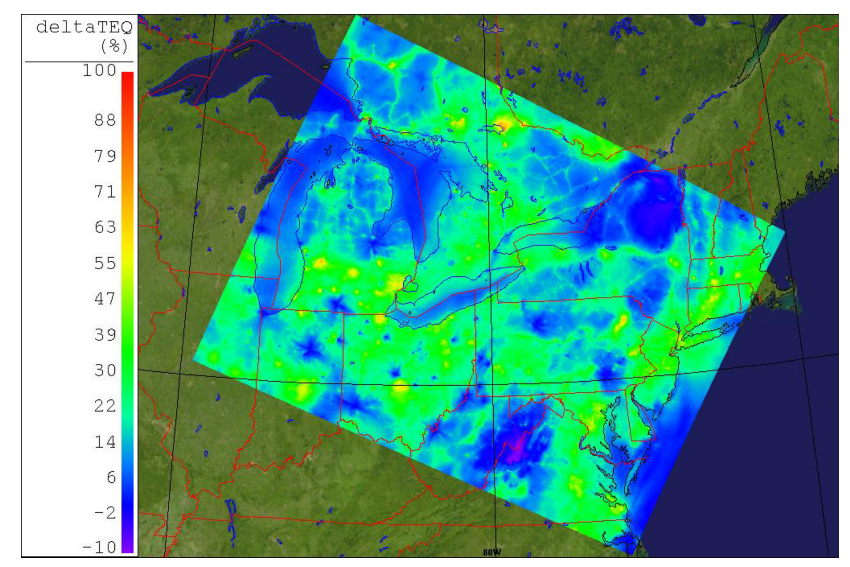

Figure 7. Average change in BaP toxic equivalents (TEQ) in ambient air during spring-summer 2009 when on-road vehicle emissions are set to zero.

certainties in emissions and atmospheric chemistry are explored in this section, and they are described in more detail in the Supplement (Sect. V).

We expect that the largest contribution to uncertainty in our results to be associated with the PAH mobile emissions. The on-road vehicle EFs for PAHs that underlay this study's inventory were taken from MOVES2014b (EPA, 2014). These factors were determined from two US reports that examined gasoline and diesel emissions separately (Kishan et al., 2008; Khalek et al., 2009). We carried out four sensitivity simulations with GEM-MACH-PAH with the BENZ and PAH emissions from on-road vehicles scaled by factors of 0.5 and 2 in both seasons. This range corresponds approximately to the 25th and 75th percentiles of the range of EFs reported in the recent peer-reviewed literature (Whaley et al., 2018b). The model responded consistently to on-road vehicle emission scaling with average changes to the vehicle contribution amount of $-5 \%$ to $-10 \%$ and $+20 \%$ to $+30 \%$, depending on species, for halved and doubled vehicle emissions, respectively (compare Tables 1 and 2). This finding suggests that the relative importance of vehicle contributions when different EFs are used remains consistent with our current results across a broad range of emissions levels. This topic is described in more detail in the Supplement (Sect. V).

Whereas the effects of emissions perturbations are straightforward to evaluate, uncertainties that arise from at- mospheric chemistry are complex to assess, because they result from secondary formation processes for atmospheric oxidants. A reduction in precursor emissions yields a non-linear change in oxidant concentrations that depends on chemistry and the physical state of the atmosphere at each location. The removal of on-road vehicle emissions induces a large range of changes in oxidant concentrations (Figs. 5 and S9). The resulting changes in BENZ and PAH concentrations as a function of changes in oxidant concentration are highly variable (e.g., Figs. S5 and S6), and some geographic areas see a net increase in PAH concentrations because reduced atmospheric oxidation of PAHs overwhelms the effect of removing vehicle emissions. However, such results were uncommon throughout the study area. For a reactive $\mathrm{PAH}$ such as pyrene, for example, $88.3 \%$ and $99.9 \%$ of model grid squares in spring-summer and fall-winter, respectively, responded to the removal of vehicle emissions with reductions in ambient PAH concentrations. Relatively unreactive benzene, on the other hand, responded to emissions reductions with ambient concentration reductions in all model grid squares.

\subsection{Human health implications}

The removal of on-road vehicle emissions would lead not only to reductions in ambient benzene and PAH concentrations (as well as in other pollutants), as demonstrated by our model results, but also to reductions in human exposure. Proximity to roadways and traffic has been linked to elevated exposure outdoors, and this has led to particular concerns for commuters (Miao et al., 2015; Yan et al., 2015; Tan et al., 2017; Lovett et al., 2018; Miri et al., 2018). Further inhalation exposure to traffic pollutants occurs in indoor environments, where infiltration of outdoor air can contribute a substantial proportion of benzene and PAH exposure (Naumova et al., 2002; Xu et al., 2016), adding to concerns about residences, schools, and workplaces that are situated near roadways.

PAH species vary in toxicity, and their mixture is often represented as a toxic equivalent concentration (TEQ), which is the sum of contributing compound concentrations that have been normalized by their carcinogenic potencies relative to BaP (Nisbet and LaGoy, 1992). The percent reduction in TEQ when on-road vehicle emissions were removed (Fig. 7) averaged $19 \%$ across the domain. The magnitudes and ge- 
ographic distribution of these TEQ reductions closely follow the reductions in simulated PAH concentrations, implying a direct toxicity benefit of mobile emissions reductions. For large urban areas and their suburbs, where both ambient concentrations and human population density are high, results herein suggest that TEQs could be reduced by values of $20 \%-60 \%$ if vehicle emissions were removed. Maximum TEQ reductions of up to $\sim 80 \%$ were predicted for some rural and suburban locations near highways (e.g., North Bay, ON; Sudbury, ON; Grand Rapids, MI; and Maumee, $\mathrm{OH}$ ).

Benzene has not been assigned a BaP toxic equivalency factor in the available literature. However, the combination of its modelled concentration and its human toxicity potential (Hertwich et al., 2001), which are approximately 1000 times larger and smaller than those of $\mathrm{BaP}$, respectively, suggests that reductions in traffic emissions would lead to similar reductions in risk for benzene as for PAHs.

Further connection of the results of this study to potential human health benefits will require careful attention to the interplay between air toxics and criteria air contaminants, since these are not often considered together in air quality research. The development, evaluation, and first application of GEMMACH-PAH makes such work possible. Another priority for future research is the improvement of emissions inventories and model process representations.

\section{Conclusions}

The previously validated GEM-MACH-PAH model was used to simulate benzene, $\mathrm{PAH}$, and other pollutant concentrations for both base case and no-mobile emissions scenarios for a densely populated region in northeastern North America. Taking the difference of the two scenarios has allowed the on-road vehicle contribution to ambient concentrations to be calculated; this effect was $4 \%-21 \%$ for benzene and PAHs and $10 \%$ for both spring-summer $\mathrm{O}_{3}$ and fall-winter $\mathrm{PM}_{10}$ on average in our southern Ontario and northeastern US model domain (variations for season and compound). Maximum seasonally averaged vehicle contributions were $74 \%$ for BENZ, $91 \%$ for PAHs, and $22 \%$ for spring-summer $\mathrm{O}_{3}$, and they were $33 \%$ for fall-winter $\mathrm{PM}_{10}$ within the model domain. These can additionally be interpreted as the relative reductions in pollutant concentrations expected with the introduction of a ZEV fleet. The chemical transport modelling of benzene and PAHs presented in this study is unprecedented in terms of combined domain size and spatial resolution, and it has demonstrated that vehicular sources of these toxic species make substantial contributions to ambient concentrations (expressed on the basis of both mass and toxic equivalents) at the urban scale. This suggests that meaningful decreases in BENZ and PAH concentrations can be achieved through on-road vehicle emission reductions. Such reductions could be achieved through a number of potential management actions, including increases in ZEV use and greater use of active transportation modes such as walking and cycling. Future work aims to include more PAH species, including secondary reaction products such as oxy- and nitroPAHs, and to improve model representation of wintertime benzene and $\mathrm{BaP}$.

Code availability. The MACH-PAH (chemistry) code is available here: https://doi.org/10.5281/zenodo.1162252 (Whaley et al., 2018c), and the GEM (meteorology model) code is available here: https://github.com/mfvalin?tab=repositories (last access: 6 March 2020). The executable for GEM-MACH-PAH is obtained by providing the chemistry library (MACH-PAH) to GEM when generating its executable.

Supplement. The supplement related to this article is available online at: https://doi.org/10.5194/acp-20-2911-2020-supplement.

Author contributions. EG is the principal investigator for this project. EG, PAM, and CHW designed the model experiment, and CHW and EG developed the model code. JZ, MDM, and CHW created the emissions files for the model simulations. CHW performed the model simulations and analysis, and CHW and EG wrote the article with support from all co-authors.

Competing interests. The authors declare that they have no conflict of interest.

Acknowledgements. The authors acknowledge the contributions of Ayodeji Akingunola, Sylvie Gravel, Wanmin Gong, Craig Stroud, and Qiong Zheng for their assistance in setting up GEM-MACHPAH (Whaley et al., 2018b). All maps were created using CMC software, SPI.

Financial support. The authors acknowledge funding from the Government of Canada's Program of Energy Research and Development (PERD; ALMITEE project led by Jeffrey R. Brook) and from Environment and Climate Change Canada's Climate Change and Air Pollution program.

Review statement. This paper was edited by Ronald Cohen and reviewed by two anonymous referees.

\section{References}

Anastasopoulos, A. T., Wheeler, A. J., Karman, D., and Kulka, R. H.: Intraurban concentrations, spatial variability, and correlation of ambient polycyclic aromatic hydrocarbons (PAH) and $\mathrm{PM}_{2.5}$, Atmos. Environ., 59, 272-283, https://doi.org/10.1016/j.atmosenv.2012.05.004, 2012. 
Aulinger, A., Matthias, V., and Quante, M.: Introducing a partitioning mechanism for PAHs into the Community Multiscale Air Quality modeling system and its application to simulating the transport of benzo(a)pyrene over Europe, J. Appl. Meteorol. Clim., 46, 1718-1730, https://doi.org/10.1175/2007JAMC1395.1, 2007.

Bidleman, T. F. and Foreman, W. T.: Vapor-particle partitioning of semivolatile organic compounds, in: Sources and Fates of Aquatic Pollutants, 27-56, American Chemical Society, 1987.

Boulton, J. W.: Emissions, air quality and health impacts of widespread electric vehicle use: literature review and relevance to the Canadian situation, Technical report, 75 Albert St, Ottawa, ON, Canada, K1P 5E7, 2016.

Center for climate and energy solutions: U.S. state clean vehicle policies, url, Center for climate and energy solutions, United States, available at: https://www.c2es.org/document/ us-state-clean-vehicle-policies-and-incentives/ (last access: 27 January 2020), 2019.

Côté, J., Desmarais, J.-G., Gravel, S., Méthot, A., Patoine, A., Roch, M., and Staniforth, A.: The Operational CMC-MRB Global Environmental Multiscale (GEM) Model. Part II: Results, Mon. Weather Rev., 126, 1397-1418, https://doi.org/10.1175/15200493(1998)126<1397:TOCMGE>2.0.CO;2, 1998a.

Côté, J., Gravel, S., Méthot, A., Patoine, A., Roch, M., and Staniforth, A.: The Operational CMC-MRB Global Environmental Multiscale (GEM) Model. Part I: Design Considerations and Formulation, Mon. Weather Rev., 126, 1373-1395, https://doi.org/10.1175/15200493(1998)126<1373:TOCMGE>2.0.CO;2, 1998 b.

Dachs, J. and Eisenreich, S. J.: Adsorption onto aerosol soot carbon dominates gas-particle partitioning of polycyclic aromatic hydrocarbons, Environ. Sci. Technol., 34, 3690-3697, https://doi.org/10.1021/es991201, 2000.

Dunbar, J. C., Lin, C. I., Vergucht, I., Wong, J., and Duran, J. L.: Estimating the contributions of mobile sources of PAH to urban air using real-time PAH monitoring, Sci. Total Environ., 279, 119, https://doi.org/10.1016/S0048-9697(01)00686-6, 2001.

ECCC: Toxic substances list: benzene, url, Environment and Climate Change Canada, Toronto, ON, Canada, available at: https://www.canada.ca/en/environment-climate-change/ services/management-toxic-substances/

list-canadian-environmental-protection-act/benzene.html

(last access: 4 June 2018), 2015.

ECCC: Air Pollutant Emissions Inventory, Overview, website, Environment and Climate Change Canada, available at: https://www.canada.ca/en/environment-climate-change/ services/pollutants/air-emissions-inventory-overview.html (last access: 24 January 2020), 2018a.

ECCC: Toxic substances list: polycyclic aromatic hydrocarbons, url, Environment and Climate Change Canada, Toronto, ON, Canada, available at: https: //www.canada.ca/en/environment-climate-change/

services/management-toxic-substances/

list-canadian-environmental-protection-act/

polycyclic-aromatic-hydrocarbons.html, last access: $30 \mathrm{Au}-$ gust $2018 \mathrm{~b}$.

ECCC: 2019 National Inventory Report 1990-2017: Greenhouse Gas Sources and Sinks in Canada, Part 3, report, Environment and Climate Change Canada, available at: http://publications.
gc.ca/collections/collection_2019/eccc/En81-4-2017-3-eng.pdf (last access: 24 January 2020), 2019a.

ECCC: Canada-US vehicle and engine emissions: 2014 to 2016 work plan, url, Environment and Climate Change Canada, Canada, available at: https://www. canada.ca/en/environment-climate-change/corporate/ international-affairs/partnerships-countries-regions/ north-america/canada-united-states-vehicle-engine-emissions. html (last access: 27 January 2020), 2019b.

energy.gov: Electric vehicle benefits, url, Office of Efficiency and Renewable Energy, United States, available at: https://www. energy.gov/eere/electricvehicles/electric-vehicle-benefits, last access: 27 January 2020.

Environment Canada and Health Canada: Priority substances list assessment report. Polycyclic aromatic hydrocarbons, report, Government of Canada, Ottawa, 1994.

EPA: User's guide to MOBILE6.1 and MOBILE6.2: Mobile source emission factor model, technical report, Air and Radiation Division, U.S. Environmental Protection Agency, 2002.

EPA: Speciation of total organic gas and particulate matter emissions from on-road vehicles in MOVES2014, technical report, Assessment and Standards Division, Office of Transport and Air Quality, U.S. Environmental Protection Agency, 2014.

EPA: Summary of Results for the 2011 National-Scale Assessment, Report, United States Environment Protection Agency, USA, avilable at: https:/www.epa.gov/sites/production/files/2015-12/ documents/2011-nata-summary-results.pdf (last access: $30 \mathrm{Au}-$ gust 2018), 2015.

Eyth, A., R. Mason, R., and Zubrow, A.: Development and Status of EPA's 2011 Modeling Platform, conference presentation, 12th CMAS Conference, 28-30 October, Chapel Hill, North Carolina, USA, available at: https://www.cmascenter.org/ conference//2013/slides/eyth_development_status_2013.pptx (last access: 20 September 2019), 2013.

Farrell, W., Weichenthal, S., Goldberg, M., Valois, M.-F., Shekarrizfard, M., and Hatsopoulou, M.: Near roadway air pollution across a spatially extensive road and cycling network, Environ. Pollut., 212, 498-507, https://doi.org/10.1016/j.envpol.2016.02.041, 2016.

Friedman, C. L. and Selin, N. E.: Long-range atmospheric transport of polycyclic aromatic hydrocarbons: a global 3-D model analysis including evaluation of Arctic sources, Environ. Sci. Technol., 46, 9501-9510, https://doi.org/10.1021/es301904d, 2012.

Galarneau, E., Makar, P. A., Sassi, M., and Diamond, M. L.: Estimation of Atmospheric Emissions of Six Semivolatile Polycyclic Aromatic Hydrocarbons in Southern Canada and the United States by Use of an Emissions Processing System, Environ. Sci. Technol., 41, 4205-4213, https://doi.org/10.1021/es062303k, 2007.

Galarneau, E., Makar, P. A., Zheng, Q., Narayan, J., Zhang, J., Moran, M. D., Bari, M. A., Pathela, S., Chen, A., and Chlumsky, R.: PAH concentrations simulated with the AURAMSPAH chemical transport model over Canada and the USA, Atmos. Chem. Phys., 14, 4065-4077, https://doi.org/10.5194/acp14-4065-2014, 2014.

Galarneau, E., Wang, D., Dabek-Zlotorzynska, E., Siu, M., Celo, V., Tardif, M., Harnish, D., and Jiang, Y.: Air toxics in Canada measured by the National Air Pollution Surveillance (NAPS) Program and their relation to ambient 
air quality guidelines, J. Air Waste Manage., 66, 184-200, https://doi.org/10.1080/10962247.2015.1096863, 2016.

Gariazzo, C., Silibelle, C., Finardi, S., Radice, P., D’Allura, A., Gherardi, M., and Cecinato, A.: PAHs Modelling over urban area of Rome: Integration of models results with experimental data, in: Air Pollution modelling and its application XXIII, edited by: Steyn, D. and Mathur, R., 349-354, Springer Proceedings in Complexity, Springer International Publishing, Switzerland, https://doi.org/10.1007/978-3-319-04379-1_56, 2014.

Gariazzo, C., Lamberti, M., Hänninen, O., Silibello, C., Pelliccioni, A., Porta, D., Cecinato, A., Gherardi, M., and Forastiere, F.: Assessment of population exposure to Polycyclic Aromatic Hydrocarbons (PAHs) using integrated models and evaluation of uncertainties, Atmos. Environ., 101, 235-245, https://doi.org/10.1016/j.atmosenv.2014.11.035, 2015.

Gentner, D. R., Jathar, S. H., Gordon, T. D., Bahreini, R., Day, D. A., El Haddad, I., Hayes, P. L., Pieber, S. M., Platt, S. M., de Gouw, J., Goldstein, A. H., Harley, R. A., Jimenez, J. L., Prévôt, A. S. H., and Robinson, A. L.: Review of Urban Secondary Organic Aerosol Formation from Gasoline and Diesel Motor Vehicle Emissions, Environ. Sci. Technol., 51, 10741093, https://doi.org/10.1021/acs.est.6b04509, 2017.

Gong, W., Makar, P. A., Zhang, J., Milbrandt, J., Gravel, S., Hayden, K. L., Macdonald, A. M., and Leaitch, W. R.: Modelling aerosol cloud meteorology interaction: A case study with a fully coupled air quality model GEM-MACH, Atmos. Environ., 115, 695-715, https://doi.org/10.1016/j.atmosenv.2015.05.062, 2015.

Government of Canada: Canada's actions to reduce emissions, url, Government of Canada, Canada, available at: https://www.canada.ca/en/services/environment/weather/

climatechange/climate-plan/reduce-emissions.html (last access: 27 January 2020), 2019.

Government of Quebec: The Zero-emission vehicle (ZEV) standard, url, Environnement et Lutte contre les changement climatique, Québec, Quebec, available at: http://www.environnement. gouv.qc.ca/changementsclimatiques/vze/index-en.htm, last access: 27 January 2020.

Hafner, W. D., Carlson, D. L., and Hites, R. A.: Influence of Local Human Population on Atmospheric Polycyclic Aromatic Hydrocarbon Concentrations, Environ. Sci. Technol., 39, 7374-7379, https://doi.org/10.1021/es0508673, 2005.

Han, X. and Naeher, L. P.: A review of traffic-related air pollution exposure assessment studies in the developing world, Environ. Int., 32, 106-120, https://doi.org/10.1016/j.envint.2005.05.020, 2006.

Harrison, R. M., Smith, D. J. T., and Luhana, L.: Source apportionment of atmospheric polycyclic aromatic hydrocarbons collected from an urban location in Birmingham, UK, Environ. Sci. Technol., 30, 825-832, https://doi.org/10.1021/es950252d, 1996.

Hertwich, E., Matelas, S., Pease, W., and McKone, T.: Human toxicity potentials for life-cycle assessment and Toxics Release Inventory risk screening, Environ. Toxicol. Chem., 20, 928-939, 2001.

Houyoux, M., Vukovich, J., and Brandmeyer, J.: Sparse Matrix Operator Kernel Emissions Modeling System-SMOKE User Manual, Technical report, Environmental Modeling Center, Research Triangle Park, North Carolina, mCNC-2002, 2002.

Jing, P., Lu, Z., Xing, J., Streets, D. G., Tan, Q., O’Brien, T., and Kamberos, J.: Response of the summertime ground-level ozone trend in the Chicago area to emission controls and temperature changes, 2005-2013, Atmos. Environ., 99, 630-640, https://doi.org/10.1016/j.atmosenv.2014.10.035, 2014.

Junge, C. E.: Basic considerations about trace constituents in the atmosphere as related to the fate of global pollutants, in: Fate of pollutants in the air and water environments, edited by: Suffet, I. H., 7-25, Wiley, New York, 1977.

Karavalakis, G., Boutsika, V., Stournas, S., and Bakeas, E.: Biodiesel emissions profile in modern diesel vehicles. Part 2: Effect of biodiesel origin on cabonyl, PAH, nitro-PAH and oxy-PAH emissions, Sci. Total Environ., 409, 738-747, https://doi.org/10.1016/j.scitotenv.2010.11.010, 2011.

Khalek, I. A., Bougher, T. L., and Merritt, P. M.: Phase 1 of the advanced collaborative emissions study, Report, Coordinating Research Council, INC., Mansell Rd, Alpharetta, GA, USA, 30022, 2009.

Kishan, S., Crews, W., Zmud, M., Fujita, E., Burnette, A., Snow, R., Santos, R., Campbell, D., Fincher, S., Bricka, S., Arnott, P., and Sabisch, M.: Kansas City PM characterization study: Final Report, Report, Assessment and Standards Division, Office of Transportation and Air Quality, U.S. EPA, and the Eastern Research Group Inc., 5608 Parkcrest Drive Suite 100, Austin, TX, USA, 2008.

Kleinman, L. I., Daum, P. H., Imre, D. G., Lee, J. H., Lee, Y.-N., Nunnermacker, L. J., Springston, S. R., WeinsteinLloyd, J., and Newman, L.: Ozone production in the New York City urban plume, J. Geophys. Res., 105, 14495-14511, https://doi.org/10.1029/2000JD900011, 2000.

Kuoppamäki, K., Setälä, H., Rantalainen, A.-L., and Kotze, D. J.: Urban snow indicates pollution originating from road traffic, Environ. Pollut., 195, 56-63, https://doi.org/10.1016/j/envpol.2014.08.019, 2014.

Lovett, C., Shirmohammadi, F., Sowlat, M., and Sioutas, C.: Commuting in Los Angeles: Cancer and non-cancer health risks of roadway, light-rail and subway transit routes, Aerosol Air Qual. Res., 18, 2363-2374, 2018.

Makar, P., Gong, W., Hogrefe, C., Zhang, Y., Curci, G., Zabkar, R. ., Milbrandt, J., Im, U., Balzarini, A., Baró, R., Bianconi, R., Cheung, P., Forkel, R., Gravel, S., Hirtl, M., Honzak, L., Hou, A., Jiménez-Guerrero, P., Langer, M., Moran, M., Pabla, B., Pérez, J., Pirovano, G., José, R. S., Tuccella, P., Werhahn, J., Zhang, J., and Galmarini, S.: Feedbacks between air pollution and weather, part 2: Effects on chemistry, Atmos. Environ., 115, 499-526, https://doi.org/10.1016/j.atmosenv.2014.10.021, 2015a.

Makar, P. A., Gong, W., Milbrandt, J., Hogrefe, C., Zhang, Y., Curci, G., Zabkar, R. ., Im, U., Balzarini, A., Baró, R., Bianconi, R., Cheung, P., Forkel, R., Gravel, S., Hirtl, M., Honzak, L., Hou, A., Jiménez-Guerrero, P., Langer, M., Moran, M., Pabla, B., Pérez, J., Pirovano, G., José, R. S., Tuccella, P., Werhahn, J., Zhang, J., and Galmarini, S.: Feedbacks between air pollution and weather, part 1: Effects on weather, Atmos. Environ., 115, 442-469, https://doi.org/10.1016/j.atmosenv.2014.12.003, 2015b.

Miao, Q., Bouchard, M., Chen, D., Rosenberg, M. W., and Aronson, K. J.: Commuting behaviors and exposure to air pollution in Montreal, Canada, Sci. Total Environ., 508, 193-198, https://doi.org/10.1016/j.scitotenv.2014.11.078, 2015.

Miri, M., Alahabadi, A., Ehrampoush, M. H., Ghaffari, H. R., Sakhvidi, M. J. Z., Eskandari, M., Rad, A., Lotfi, M. H., and Sheikhha, M. H.: Environmental determinants of poly- 
cyclic aromatic hydrocarbons exposure at home, at kindergartens and during a commute, Environ. Int., 118, 266-273, https://doi.org/10.1016/j.envint.2018.06.006, 2018.

Moran, M., Scholtz, M., Slama, C., Dorkalam, A., Taylor, A., Ting, N., Davies, D., Makar, P., and Venkatesh, S.: An Overview of CEPS1.0: Version 1.0 of the Canadian Emissions Processing System for Regional-Scale Air Quality Models, Proc. 7th awma emission inventory symp., Air and Waste Management Association, Pittsburgh, USA, Research Triangle Park, North Carolina, USA, 1997.

Moran, M., Menard, S., Gravel, S., Pavlovic, R., and Anselmo, D.: RAQDPS Versions 1.5.0 and 1.5.1: Upgrades to the CMC Operational Regional Air Quality Deterministic Prediction System Released in October 2012 and February 2013, Technical report, Canadian Meteorological Centre, Canadian Meteorological Centre, Dorval, Quebec, 2013.

Moran, M. D., Ménard, S., Talbot, D., Huang, P., Makar, P. A., Gong, W., Landry, H., Gravel, S., Gong, S., Crevier, L.-P., Kallaur, A., and Sassi, M.: Particulate-matter forecasting with GEM-MACH15, a new Canadian air-quality forecast model, in: Air pollution modelling and its application XX, edited by: Steyn, D. G. and Rao, S. T., p 289-292, Springer, Dordrecht, 2010.

Naumova, Y., Eisenreich, S., Turpin, B., Weisel, C., Morandi, M., Colome, S., Totten, L., Stock, T., Winer, A., Alimokhtari, S., Kwon, J., Shendell, D., Jones, J., Maberti, S., and Wall, S.: Polycyclic aromatic hydrocarbons in the indoor and outdoor air of three cities in the U.S., Environ. Sci. Technol., 36, 2552-2559, 2002.

Nielsen, T.: Traffic contribution of polycyclic aromatic hydrocarbons in the center of a large city, Atmos. Environ., 30, 34813490, https://doi.org/10.1016/1352-2310(96)00096-9, 1996.

Nisbet, I. and LaGoy, P.: Toxic equivalency factors (TEFs) for polycyclic aromatic hydrocarbons (PAHs), Regul. Toxicol. Pharm., 16, 290-300, 1992.

NPRI: National Pollutant Release Inventory, website, Environment and Climate Change Canada, 2016.

Pachón, J. E., Sarmiento, H., and Hoshiko, T.: Health risk represented by inhaling polycyclic aromatic hydrocarbons (PAH) during daily commuting involving using a high traffic flow route in Bogotá, Rev. Salud Publica (Bogota), 3, 198-407, 2013.

Reid, H. and Aherne, J.: Staggering reductions in atmospheric nitrogen dioxide across Canada in response to legislated transportation emissions reductions, Atmos. Environ., 146, 252-260, https://doi.org/10.1016/j.atmosenv.2016.09.032, 2016.

San José, R., Pérez, J. L., Callén, M. S., López, J. M., and Amstral, A.: BaP (PAH) air quality modelling exercise over Zaragoza (Spain) using an adapted version of WRF-CMAQ model, Environ. Pollut., 183, 151-158, https://doi.org/10.1016/j.envpol.2013.02.025, 2013.

Sassi, M., Mehrez, S., Racine, J., and Cousineau, S.: 2010 Canadian CAC emission inventories for the air quality modelling platform supporting policy regulations, conference presentation, 21st Intern. Emissions Inventory Conference, 13-17 April, San Diego, California, USA, available at: http://www.epa.gov/ttn/ chief/conference/ei21/session1/sassi.pdf (last access: 20 September 2019), 2015.

Shen, H., Tao, S., Wang, R., Wang, B., Shen, G., Li, W., Su, S., Huang, Y., Wang, X., Liu, W., Li, B., and Sun, K.: Global time trends in PAH emissions from motor vehicles, Atmos. Environ.,
45, 2067-2073, https://doi.org/10.1016/j.atmosenv.2011.01.054, 2011.

Sillman, S.: The use of $\mathrm{NO}_{y}, \mathrm{H}_{2} \mathrm{O}_{2}$, and $\mathrm{HNO}_{3}$ as indicators for $\mathrm{O}_{3}-\mathrm{NO}_{x}$-VOC sensitivity in urban locations, J. Geophys. Res., 1001, 14175-14188, https://doi.org/10.1029/94JD02953, 1995.

Sillman, S. and West, J. J.: Reactive nitrogen in Mexico City and its relation to ozone-precursor sensitivity: results from photochemical models, Atmos. Chem. Phys., 9, 3477-3489, https://doi.org/10.5194/acp-9-3477-2009, 2009.

Sims, R., Schaeffer, R., Creutzig, F., nez, X. C.-N., D’Agosto, M., Dimitriu, D., Meza, M. J. F., Fulton, L., Kobayashi, S., Lah, O., McKinnon, A., Newman, P., Ouyang, M., Schauer, J. J., Sperling, D., and Tiwari, G.: Chapter 8: Transport, in: Climate Change 2014: Mitigation of Climate Change. Contribution of Working Group III to the Fifth Assessment Report of the Intergovernmental Panel on Climate Change, edited by: Edenhofer, O., PichsMadruga, R., Sokona, Y., Farahani, E., Kadner, S., Seyboth, K., Adler, A., Baum, I., Brunner, S., Eickemeier, P., Kriemann, B., Savolainen, J., Schlömer, S., von Stechow, C., Zwickel, T., and Minx, J., Cambridge University Press, Cambridge, United Kingdom and New York, NY, USA, 2014.

Stroud, C. A., Zaganescu, C., Chen, J., McLinden, C. A., Zhang, J., and Wang, D.: Toxic volatile organic air pollutants across Canada: multi-year concentration trends, regional air quality modelling and source apportionment, J. Atmos. Chem., 73, 137164, https://doi.org/10.1007/s10874-015-9319-z, 2016.

Tan, S., Roth, M., and Velasco, E.: Particle exposure and inhaled dose during commuting in Singapore, Atmos. Environ., 170, 245-258, 2017.

Thackray, C. P., Friedman, C. L., Zhang, Y., and Selin, N. E.: Quantitative Assessment of Parametric Uncertainty in Northern Hemisphere PAH Concentrations, Environ. Sci. Tech. Lett., 14, 91859193, https://doi.org/10.1021/acs.est.5b01823, 2015.

Transport Canada: Zero-emission vehicles, url, Government of Canada, Canada, available at: https:/www.tc.gc.ca/en/services/ road/innovative-technologies/zero-emission-vehicles.html (last access: 27 January 2020), 2019.

U.S. Environmental Protection Agency: 2017 and later model year light-duty vehicle greenhouse gas emissions and corporate average fuel economy standards, final rule, Fed. Regist.n, available at: https://www.gpo.gov/fdsys/pkg/FR-2012-10-15/ pdf/2012-21972.pdf (last access: 20 September 2019), 2012.

US EPA: 2014 national cancer risk by pollutant, spreadsheet, U.S. Environmental Protection Agency, available at: http://www.epa.gov/sites/production/files/2018-08/nata2014v2_ national_cancerrisk_by_tract_poll.xlsx (last access: 20 September 2019), 2002.

US EPA: 2014 National Emissions Inventory, website, U.S. Environmental Protection Agency, available at: https://www.epa.gov/air-emissions-inventories/ 2014-national-emissions-inventory-nei-data (last access: 20 September 2019), 2018.

Wang, J. M., Jeong, C.-H., Zimmerman, N., Healy, R. M., Hilker, N., and Evans, G. J.: Real-world emission of particles from vehicles: volatility and the effects of ambient temperature, Environ. Sci. Technol., 51, 4081-4090, https://doi.org/10.1021/acs.est.6b05328, 2017.

Whaley, C. H., Makar, P. A., Shephard, M. W., Zhang, L., Zhang, J., Zheng, Q., Akingunola, A., Wentworth, G. R., Murphy, J. G., 
Kharol, S. K., and Cady-Pereira, K. E.: Contributions of natural and anthropogenic sources to ambient ammonia in the Athabasca Oil Sands and north-western Canada, Atmos. Chem. Phys., 18, 2011-2034, https://doi.org/10.5194/acp-18-2011-2018, 2018a.

Whaley, C. H., Galarneau, E., Makar, P. A., Akingunola, A., Gong, W., Gravel, S., Moran, M. D., Stroud, C., Zhang, J., and Zheng, Q.: GEM-MACH-PAH (rev2488): a new high-resolution chemical transport model for North American polycyclic aromatic hydrocarbons and benzene, Geosci. Model Dev., 11, 2609-2632, https://doi.org/10.5194/gmd-11-2609-2018, 2018 b.

Whaley, C., Galarneau, E., Makar, P., Moran, M., Stroud, C., Gong, W., and Gravel, S.: GEM-MACH-PAH, rev2488 (Version rev2488), Geoscientific Model Development, Zenodo, https://doi.org/10.5281/zenodo.1162252, 2018c.

WHO: Health effects of transport-related air pollution, Report, World Health Organization, Denmark, 2005.

Xu, J., Szyszkowicz, M., Jovic, B., Cakmak, S., Austin, C., and Zhu, J.: Estimation of indoor and outdoor ratios of selected volatile organic compounds in Canada, Atmos. Environ., 141, 523-531, 2016.

Yan, C., Zheng, M., Yang, Q., Zhang, Q., Qiu, X., Zhang, Y., Fu, H., Li, X., Zhu, T., and Zhu, Y.: Commuter exposure to particulate matter and particle-bound PAHs in three transportation modes in Beijing, China, Environ. Pollut., 204, 199-206, 2015.
Zhang, J., Wang, P., Li, J., Mendola, P., Sherman, S., and Ying, Q.: Estimating population exposure to ambient polycyclic aromatic hydrocarbon in the United States - Part II: Source apportionment and cancer risk assessment, Environ. Int., 97, 163-170, https://doi.org/10.1016/j.envint.2016.08.024, 2016.

Zhang, J., Li, J., Wang, P., Chen, G., Mendola, P., Sherman, S., and Ying, Q.: Estimating population exposure to ambient polycyclic aromatic hydrocarbon in the United States - Part I: Model development and evaluation, Environ. Int., 99, 263-274, https://doi.org/10.1016/j.envint.2016.12.002, 2017.

Zhang, K. and Batterman, S.: Air pollution and health risks due to vehicle traffic, Sci. Total Environ., 450-451, 307-316, https://doi.org/10.1016/j.scitotenv.2013.01.074, 2013.

Zhang, Q., Yuan, B., Shao, M., Wang, X., Lu, S., Lu, K., Wang, M., Chen, L., Chang, C.-C., and Liu, S. C.: Variations of ground-level $\mathrm{O}_{3}$ and its precursors in Beijing in summertime between 2005 and 2011, Atmos. Chem. Phys., 14, 6089-6101, https://doi.org/10.5194/acp-14-6089-2014, 2014.

Zimmerman, N., Wang, J. M., Jeong, C.-H., Ramos, M., Hilker, N., Healy, R. M., Sabaliauskas, K., Wallace, J. S., and Evans, G. J.: Field measurements of gasoline direct injection emission factors: spatial and seasonal variability, Environ. Sci. Technol., 50, 20352043, https://doi.org/10.1021/acs.est.5b04444, 2016. 